\title{
COUVELAIRE UTERUS WITHOUT PLACENTAL ABRUPTION: A RARE CASE REPORT
}

Shreedevi Kori ${ }^{1}$, S. R. Mudanur ${ }^{2}$, Neelamma Patil ${ }^{3}$, Aruna S. N ${ }^{4}$, Aishwarya J5, Kewal Patil ${ }^{6}$

\section{HOW TO CITE THIS ARTICLE:}

Shreedevi Kori, S. R. Mudanur, Neelamma Patil, Aruna S. N, Aishwarya J, Kewal Patil. "Couvelaire Uterus without Placental Abruption: A Rare Case Report". Journal of Evolution of Medical and Dental Sciences 2014; Vol. 3, Issue 38, August 25; Page: 9787-9789, DOI: 10.14260/jemds/2014/3267

ABSTRACT: A case of primigravida with 39 weeks of gestation with gestational hypertension and mild anemia with fetal distress having couvelaire uterus without evidence of abruptio placentae is reported. Couvelaire uterus is commonly seen in association with abruptio placenta or complicated with coagulopathy. Here by reporting a rare presentation of couvelaire uterus without any risk factors and diagnosed incidentally during caesarean section.

KEYWORDS: Couvelaire uterus, abruptio placenta

INTRODUCTION: Couvelaire uterus, named after the French obstetrician in view of his research work on the anatomy of pregnant uterus with uterine hemorrhages. This results due to extravasation of blood into the uterine musculature and beneath the peritoneum and imparting the classical appearance of a dark purple coloured ecchymotic uterus. ${ }^{1}$ It usually occurs in association with abruption, placenta praevia, coagulopathy, preeclampsia and eclampsia.2, 3

Here we report a rare case of couvelaire uterus without any features of placental abruption and association with other risk factors. It' s usually diagnosed incidentally during caesarean section and not in ultrasonography.

CASE REPORT: A 29 yr old primigravida residing in Bijapur came with 9 completed months of amenorrhea with complaints of pain in the lower abdomen since 10 hours prior to admission. She was appreciating fetal movements well.

Obstetric history-Married life-5 yrs, non-consanguinous marriage. She conceived spontaneously and her $1^{\text {st }}$ and $2^{\text {nd }}$ trimesters were uneventful. She was diagnosed with gestational hypertension and mild anemia at the time of admission. Her menstrual cycles were regular. Last menstrual period-unknown and according to 10 weeks scan expected date of delivery was $20 / 5 / 2014$.

\section{On Examination:}

PR-94/min, BP-140/92mm Hg, urine albumin-nil, mild pallor and bilateral pedal edema was present. Breast, thyroid and spine normal. Cardiovascular and respiratory system were clinically normal. Per abdomen-uterus term size, 1-2 contractions/10-15"/10', vertex in the lower pole, FHS was regular. Per vagina-Cervix was partially effaced and $2 \mathrm{cms}$ dilated with presenting part at -1 station and can be pushed to 0.Pelvis was adequate.

Diagnosis was primigravida with 39 weeks of gestation with vertex presentation with gestational hypertension with mild anemia. Patient was taken for Emergency LSCS under spinal anesthesia and an alive female baby of weight $2.9 \mathrm{~kg}$ was delivered at $11 \mathrm{pm}$ on $13 / 5 / 2014$. 
INDICATION: Fetal distress with persistent variable decelerations Operative findings were thick meconium stained liquor, LOT. Couvelaire uterus involving both anterior and posterior surface of uterus, placenta fundal and anterior, no evidence of placental abruption or retroplacental clots. No postpartum hemorrhage. Intra and post-operative periods were uneventful and patient was discharged on $8^{\text {th }}$ post- operative day after suture removal. Baby was kept for observation in NICU for a day in view of thick meconium and then shifted mother side.
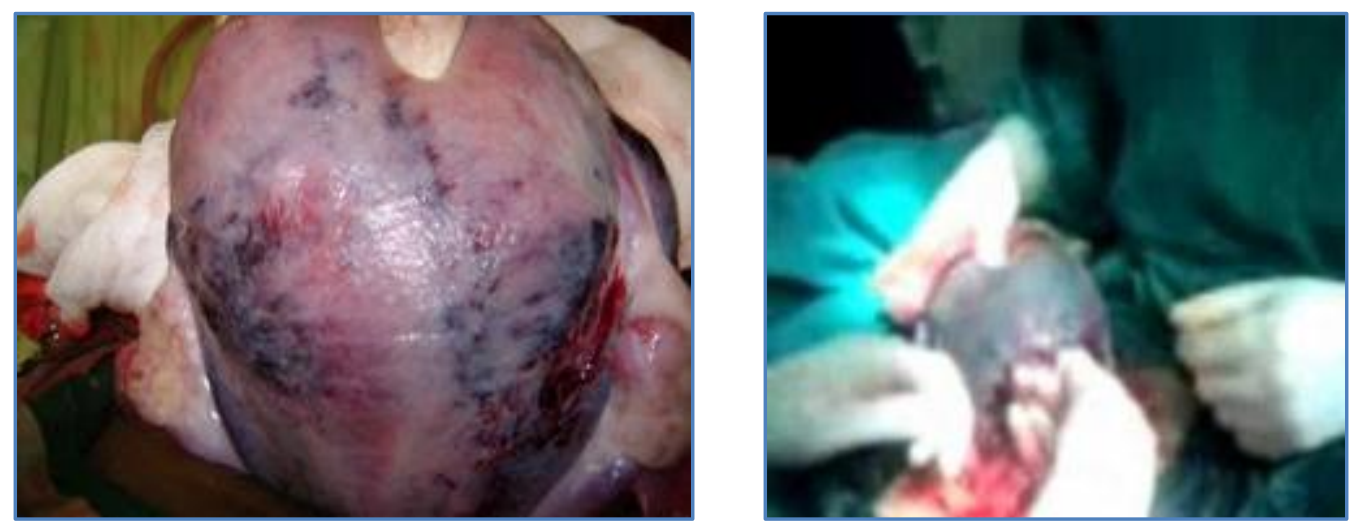

Couvelaire Uterus intra operative picture

\section{INVESTIGATIONS:}

$\mathrm{Hb}-9.2 \mathrm{~g} / \mathrm{dl}$.

RBC-4.2million/cmm.

TC-14, 400 cells/cmm.

Platelet count-1.9lakhs.

MCH-23pg.

MCV-68fl.

MCHC-37g/dl.

RBS-88mg/dl

PIH profile-normal.

Blood group-Bpositive.

USG report.

$1^{\text {st }}$ trimester scan-CRL-3.4CM, 10 wks scan with good fetal cardiac activity and expected EDD $-20 / 5 / 2014$

2 nd trimester scan -SLIUG of 20 weeks with placenta anterior, grade 1 maturity, liquor normal.

DISCUSSION: Uteroplacental apoplexy is a rare but nonfatal complication of several forms of placental abruption. Placental abruption complicates about $1 \%$ of pregnancies. The key factor in the pathophysiology is hemorrhage at the decidual-placental interface. It progresses to and infiltrates the wall of the uterus. It characteristically shows ecchymoses on serosal surface. Sometimes bleeding may likewise occur between the layers of broad ligament and the muscle bundles of the uterine wall are heavily infiltrated with extravagated blood and edema fluid.

It is a syndrome than can only be diagnosed by direct visualisation or biopsy or both and very rarely by ultrasonography.4, 5 It is commonly associated with abruption, coagulopathy and occurs as a 
complication of severe preeclampsia or eclampsia. Hence it was thought to be caused by a toxin produced by the placenta during abruption or caused by an obstruction to venous outflow. Couvelaire uterus is not an indication of hysterectomy. In spite of extravasation, uterus gets well contracted..$^{6-8}$

CONCLUSION: Couvelaire uterus is a rare non- fatal complication of severe placental abruption associated in conjunction with preeclampsia, coagulopathy, placenta praevia, uterine rupture and amniotic fluid embolism. There by we have presented a rare case of couvelaire uterus without abruption and any of the conjunctive factors.

\section{REFERENCES:}

1. JL Hubbard, SB Hosmer. Couvelaire uterus. J Am Osteopath Assoc Sep 1997; (9): 536-537.

2. Oyelesey Y, Ananth CV. Placental abruption. Obstet Gynecol;108 (4):1005-1016

3. Hall D. R. Abruptio placenta. Semin Protocol 2009; 33 (3): 189-195.

4. Habek D, Selthofer R. Uteroplacental apoplexy. Wien Klin Wochenschr 2008; 120 (3-4): 88.

5. Couvelaire uterus. Minn Med 1965; 48 (10): 1391.

6. Cunningham FG, Leveno KL, Bloom SL. Obstetrical haemorrhage, Williams obstetrics-23rd edition, NY: Mcgraw -Hill;2010:chap35.

7. Eskes TK. Abruptio placenta. Eur J Obstet Gynecol Reprod Biol 1997; 75 (1): 63-70

8. Mc Henry AG. Acquired fibrogenemia with couvelaire uterus. J La State Med Soc 1956; 108 (5): 169-171.

\section{AUTHORS:}

1. Shreedevi Kori

2. S. R. Mudanur

3. Neelamma Patil

4. Aruna S. N.

5. Aishwarya J.

6. Kewal Patil

\section{PARTICULARS OF CONTRIBUTORS:}

1. Senior Resident, Department of Obstetrics and Gynaecology, BLDE's University Shri B. M. Patil Medical College \& Research Centre, Bijapur.

2. Professor, Department of Obstetrics and Gynaecology, BLDE's University Shri B. M. Patil Medical College, Research Centre, Bijapur.

3. Associate Professor, Department of Obstetrics and Gynaecology, BLDE's University Shri B. M. Patil Medical College.

4. Assistant Professor, Department of Obstetrics and Gynaecology, BLDE's University Shri B. M. Patil Medical College, Research Centre, Bijapur.
5. Post Graduate, Department of Obstetrics and Gynaecology, BLDE's University Shri B. M. Patil Medical College \& Research Centre, Bijapur.

6. Post Graduate, Department of Obstetrics and Gynaecology, BLDE's University Shri B. M. Patil Medical College \& Research Centre, Bijapur.

\section{NAME ADDRESS EMAIL ID OF THE CORRESPONDING AUTHOR:}

Dr. Shreedevi Kori, Senior Resident, Department of Obstetrics and Gynaecology, BLDE University's Shri B.M. Patil Medical College and Research Center, Bijapur.

Email: shree_kori@yahoo.com

Date of Submission: 27/07/2014. Date of Peer Review: 28/07/2014. Date of Acceptance: 19/08/2014. Date of Publishing: 23/08/2014. 